\title{
Alterations in the Transcriptional Profile of the Liver Tissue and the Therapeutic Effects of Propolis Extracts in Alcohol-induced Steatosis in Rats
}

\author{
MANHONG YE ${ }^{1}$, MENGTING XU ${ }^{1}$, CHAO $\mathrm{JI}^{2}$, JIAN JI ${ }^{2}$, FUBIAO $\mathrm{JI}^{2}$, \\ WANHONG WEI ${ }^{3}$, SHENGMEI YANG ${ }^{3}$ and BIN $\mathrm{ZHOU}^{4}$ \\ ${ }^{1}$ College of Bioscience and Biotechnology, Yangzhou University, Yangzhou 225009, Jiangsu Province, China \\ ${ }^{2}$ Fubiao Biotech Co., Ltd., Huai-an 211799, Jiangsu Province, China \\ ${ }^{3}$ Joint International Research Laboratory of Agricultural \& Agri-Product Safety, \\ Yangzhou University, Yangzhou 225009, Jiangsu Province, China \\ ${ }^{4}$ College of Animal Science and Technology, Yangzhou University, Yangzhou 225009, Jiangsu Province, China
}

Manuscript received on July 2, 2018; accepted for publication on January 8, 2019

\begin{abstract}
How to cite: YE MH, XU MT, JI C, JI J, JI FB, WEI WH, YANG SM AND ZHOU B. 2019. Alterations in the Transcriptional Profile of the Liver Tissue and the Therapeutic Effects of Propolis Extracts in Alcohol-induced Steatosis in Rats. An Acad Bras Cienc 91: e20180646. DOI 10.1590/0001-3765201920180646.

Abstract: The hepatoprotective effects of the ethanolic extracts of propolis (EEP) on alcohol-induced liver steatosis were investigated in Wistar rats. Chronic alcoholic fatty liver was induced by administration of $52 \%$ alcohol to male Wistar rats at the dose of $1 \%$ body weight for 7 weeks. Then animals were simultaneously treated with $50 \%$ ethanol solutions of EEP or normal saline at the dose of $0.1 \%$ body weight for 4 further weeks. Serological analyses and liver histopathology studies were performed to investigate the development of steatosis. Microarray analysis was conducted to investigate the alterations of hepatic gene expression profiling. Our results showed that 4-week treatment of EEP helped to restore the levels of various blood indices, liver function enzymes and the histopathology of liver tissue to normal levels. Results from the microarray analysis revealed that the hepatic expressions of genes involved in lipogenesis were significantly down-regulated by EEP treatment, while the transcriptional expressions of functional genes participating in fatty acids oxidation were markedly increased. The ability of EEP to reduce the negative effects of alcohol on liver makes propolis a potential natural product for the alternative treatment of alcoholic fatty liver.
\end{abstract}

Key words: fatty acid oxidation, hepatoprotective effects, lipogenesis, propolis extracts, steatosis.

\section{INTRODUCTION}

Alcohol-induced fatty liver disease (AFLD) is a metabolic disturbance caused by alcohol overconsumption. It is the major cause for chronic liver diseases throughout the world (Gao and Bataller 2011). Among the wide spectrum of liver

Correspondence to: Bin Zhou

E-mail: bzhou@yzu.edu.cn

ORCid: https://orcid.org/0000-0002-0824-964X injuries caused by AFLD, fatty liver (also known as steatosis) is the first stage (Donohue 2007). The excessive lipid accumulation in the liver increases the risk of developing such pathologies as steatohepatitis, fibrosis, cirrhosis, and finally the end-stage hepatocellular carcinoma (Altamirano and Bataller 2011). Despite the profound health impact of AFLD, limited therapies are available, including abstinence, nutritional support, and 
corticosteroids (O’Shea et al. 2010). Since alcoholelicited fatty liver is the initial and reversible stage of AFLD (Purohit et al. 2009), it is vital to develop targeted nutritional and/or pharmacological agents that can alleviate hepatic lipid accumulation and decrease susceptibility of the liver to more advanced forms of liver injuries.

Propolis is a complex of various phytochemicals, especially rich in phenolic acids and flavonoids, with remarkable pharmacological, therapeutic and biological activities (Oses et al. 2016, Wagh 2013), such as anti-microbial, antioxidant, anti-inflammation, and anti-tumor effects. The beneficial roles of propolis, especially the ethanolic extracts of propolis (EEP), on a broad range of hepatic damages have been demonstrated (Andritoiu et al. 2014, Babatunde et al. 2015, Lin et al. 1997, Nakajima et al. 2016, Orsolic et al. 2012, Wali et al. 2015). In recent years, quite a few investigations have reported that plantoriginated polyphenols could attenuate alcoholic liver injury (Liu et al. 2014, Park et al. 2013, Sun et al. 2016, Wang et al. 2015). The polyphenoids-rich properties of EEP lead us to hypothesize that EEP will function in protection against alcohol-induced liver injury. Microarray analysis is a useful tool to detect altered gene expressions caused by chronic ethanol ingestion (French et al. 2005). However, little is known about the overall hepatic expression profile after the treatment of EEP.

In the present study, a rat model of alcoholinduced fatty liver was established. Then, we investigated the therapeutic potential of EEP against alcohol-induced fatty liver through the measurement of plasma levels of liver marker enzymes and observation of hepatic pathological sections. Microarray assay was also performed on the liver tissue in an effort to explore candidate genes that might contribute to the hepatoprotective effects of EEP on fatty liver.

\section{MATERIALS AND METHODS}

\section{ETHICS STATEMENT}

The care and treatment of experimental animals were approved by the Animal Ethical and Welfare Committee of Yangzhou University.

\section{PROPOLIS EXTRACTION}

Propolis used in the present study was Chinese poplar propolis provided by Fubiao Biotech Co., Ltd., Huai-an, China. EEP was prepared by following the standard protocol. Briefly, about $100 \mathrm{~g}$ of ground raw propolis was extracted with three $400 \mathrm{~mL}$ portions of $80 \%$ ethanol at room temperature with constant agitation for $72 \mathrm{~h}$. The combined suspensions were filtered first before being frozen in order to get rid of the wax, and then subjected to distillation in a rotary vacuum evaporator at $40^{\circ} \mathrm{C}$ to remove the solvent and obtain the dried EEP.

\section{CHEMICAL ANALYSIS AND ESTIMATION OF TOTAL FLAVONOID CONTENT IN EEP}

EEP was analyzed with GC-MS on a HP 6890 gas chromatograph system with mass selective detector MSD 5973 (Agilent Technologies Inc., Santa Clara, CA, USA) equipped with HP5-MS capillary column according to the procedure described by Isidorov et al (Isidorov et al. 2014). Total flavonoids were determined in triplicates by the colorimetric assay of Kim et al. (2003).

\section{EXPERIMENTAL DESIGN AND SAMPLING}

A total of 24 male Wistar rats (22-week old, weighing $344.43 \pm 38.49 \mathrm{~g}$ ) were purchased from the Comparative Medical Centre of Yangzhou University, Yangzhou, China. Animals were maintained on a 12:12 h light:dark cycle at a temperature of $22 \pm 2{ }^{\circ} \mathrm{C}$ and $50-70 \%$ relative humidity. All animals were allowed free access to commercial standard rodent diet (SLAC Laboratory 
Animal Co. Ltd., Shanghai, China) and tap water during the whole experiment.

The scheme of the study was explained in Figure 1. The source of alcohol was 52\% erguotou wine produced by Bejing Red Star Co., Ltd. (Bejing, China) and composed of 52\% alcohol and $48 \%$ water. For the evaluation of the therapeutic effects of EEP, $50 \%$ ethanol solution of EEP (w/v) was used. The dose for the gavage of normal saline $(0.9 \% \mathrm{NaCl}$ solution, $\mathrm{NS})$ and alcohol was $1 \%$ of body weight. EEP was gavaged at the dose of $0.1 \%$ body weight. Sampling was carried out at two timepoints: (1) at the end of the $7^{\text {th }}$ experimental week; (2) at the end of $11^{\text {st }}$ experimental week. Blood samples and liver tissues were collected for the analysis of serum indices and the preparation of paraffin sections, respectively. After an overnight fast, animals were anesthetized by intraperitoneal injection of sodium pentobarbital $(150 \mathrm{mg} / \mathrm{kg})$. Blood sample was collected from the abdominal aorta. Organ (heart, liver, spleen, kidney, and testis) weights and the relative organ weights (the percentage of organ weight to body weight) were recorded. Paraffin sections of the liver tissue were prepared for histopathological investigation. Additionally, for each individual in sub-groups ATEEP and AT-NS, about 1-2 g liver tissue from the right anterior lobe of the liver was snap-frozen in liquid nitrogen and then preserved at $-80^{\circ} \mathrm{C}$ for the gene expression analysis.

\section{BIOCHEMICAL ASSAYS AND MEASUREMENT OF THE TG CONTENT IN LIVER}

Plasma levels of alanine aminotransferase (ALT), aspartate aminotransferase (AST), alkaline phosphatase (ALP), triglyceride (TG), and total cholesterol (TC) were determined on an Automated Chemistry Analyzer (Boeki Medical System, Tokyo, Japan). The contents of TG in the liver tissue obtained at the end of the $11^{\text {st }}$ experimental week were determined using a commercial kit (Biosino Bio-Technology and Science Inc., Beijing, China).

\section{MICROARRAY ANALYSIS}

Microarray analysis was performed on two pooled RNA samples from sub-groups AT-EEP and ATNS using Whole Rat Genome Oligo Microarrays (Agilent Technologies, CA, USA) by staff at the

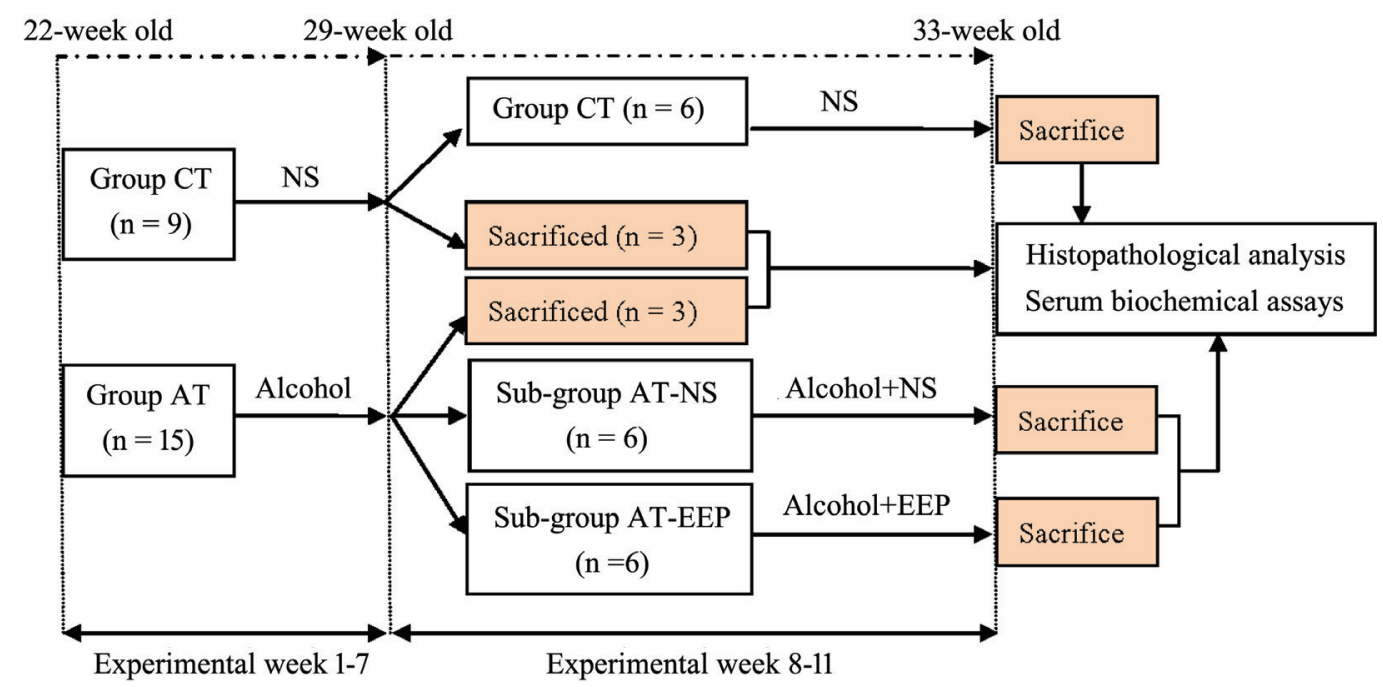

Figure 1 - Experimental design of the present study. Group CT, control; Group AT, treated with alcohol; Subgroup AT-NS and Sub-group AT-EEP, treated with alcohol and co-administered with normal saline (NS) and EEP, respectively. 
Shanghai Biotechnology Corporation, Shanghai, China. Data analysis focused on differentially expressed genes (DEGs) with a present flag value for both samples and the expression of which changed by 2.0-fold or greater. Functional analysis for DEGs was conducted with Database for Annotation, Visualization and Integrated Discovery (DAVID) (Huang et al. 2009).

\section{STATISTICAL ANALYSES}

Data were presented as the mean \pm S.E. Differences between group CT and group AT at the end of the $7^{\text {th }}$ experimental week were determined by unpaired Student's t-test. Differences among group CT, subgroup AT-NS, and sub-group AT-EEP at the end of the $11^{\text {st }}$ experimental week were determined by ANOVA for repeated measures using SPSS software version 13.0 (SPSS Inc., Chicago, USA). Post hoc testing for group comparisons was performed using the LSD test. Statistical significance was considered at $p<0.05$.

\section{DATA AVAILABILITY}

Gene expression data are available at GEO with the accession number: GSE100173.

\section{RESULTS}

\section{THE MAIN CONSTITUENTS IN EEP}

The ethanolic extract of $100 \mathrm{~g}$ of raw propolis produced approximately $25 \mathrm{~g}$ of dry EEP (a yield of approximately $25 \%$ ). Spectrophotometric analysis showed that EEP was rich in flavonoids and the total flavonoids content of EEP was averagely 204.5 mg RE per g of dry EEP. The GC-MS analysis of EEP identified 24 chemical compounds mainly including flavonoids (19.02\%), esters of aliphatic and aromatic acids (14.02\%), and alcohols (8.21\%) (Table SI - Supplementary Material). Of which, chrysin, galangin, pinocembrine, and pinostrobin are the main flavanoids in EEP.
BODY WEIGHT (BW), ORGAN WEIGHT, AND RELATIVE ORGAN WEIGHT

There were no significant differences in the initial BWs of rats used in the present study. During the 11-week experimental period, no significant differences in BWs were detected among all groups. However, intragastric administration of alcohol did lead to a decreasing tendency in BWs and animals in group $\mathrm{CT}$ showed the highest BWs among all groups during almost the whole trial (Figure S1 Supplementary Material).

Our results showed that alcohol treatment had no significant influences on the final organ weights of rats (Table SII). As to the relative organ weight, significant differences in relative liver weight (RLW) were detected after 7-week treatment of alcohol. Rats in group AT had significantly higher RLW $(4.17 \pm 0.08 \%)$ than that in group CT $(3.72 \pm 0.10 \%)(p<0.05)$. After 4 -week further treatment of alcohol, sub-group AT-NS had the lowest liver weight and the highest RLW in value when compared with sub-group AT-EEP and group CT. However, the differences were no longer statistically significant.

PLASMA BIOCHEMICAL PARAMETERS

After 7-week treatment of alcohol, rats in group AT were characterized by significantly higher ALT level when compared with animals in group CT, which indicated the ongoing liver damage caused by chronic alcohol consumption. The AST and ALP levels in group AT only showed a tendency of increasing (Figure 2a). Four-week further treatment of alcohol caused severe liver injury, which was demonstrated by the significantly higher ALT level in sub-group AT-NS than that in sub-group ATEEP and group CT (Figure 2b). On the other hand, co-administration of EEP with alcohol showed a favorable tendency to reduce plasma ALT, AST, and ALP levels. No significant differences were 

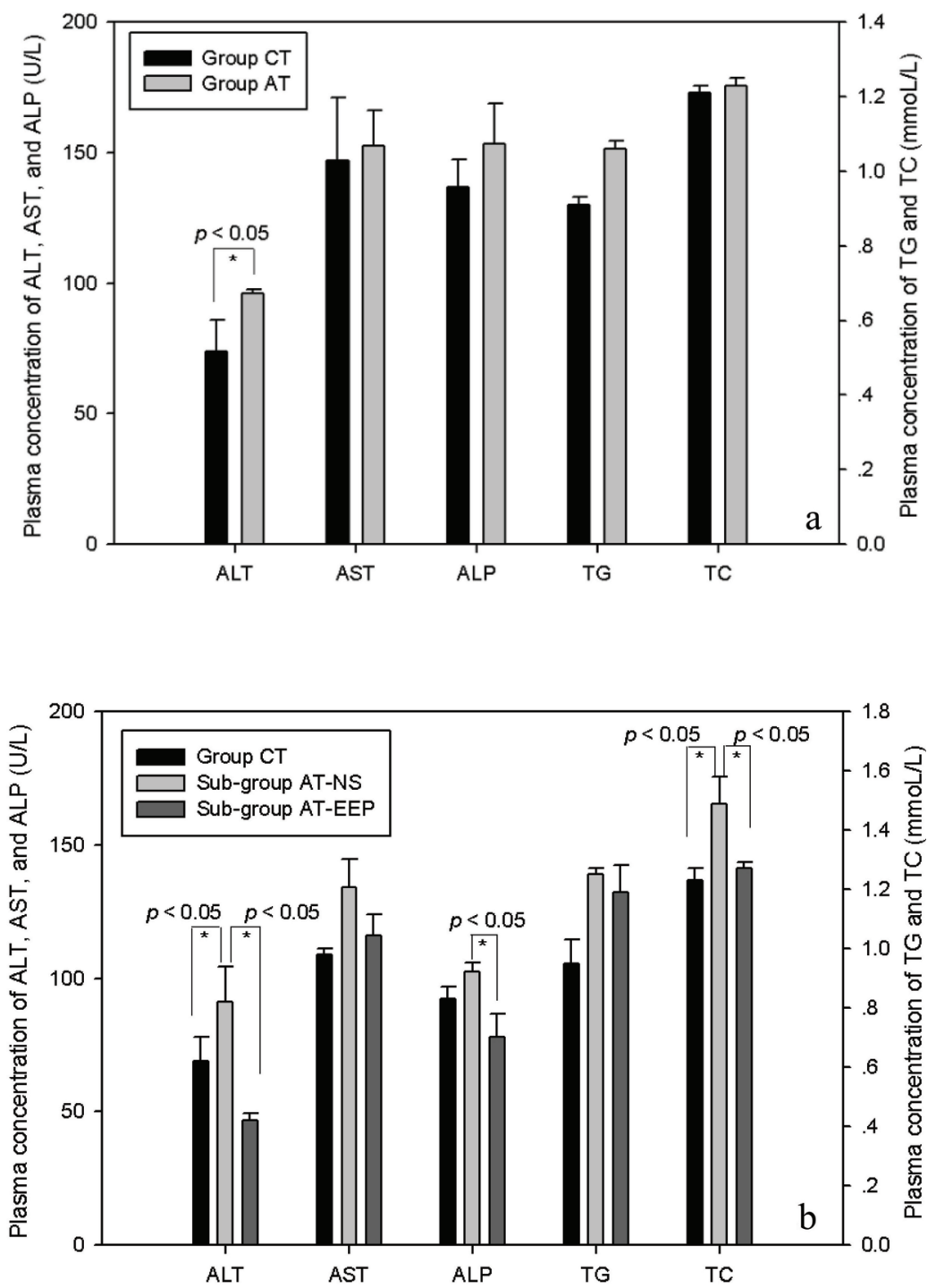

Figure 2 - Comparison of plasma parameters between different groups. Values are expressed as mean \pm S.E. Group CT, control; Group AT, treated with alcohol; Subgroup AT-EEP and Sub-group AT-NS, treated with alcohol and co-administered with EEP and normal saline, respectively. a) Comparison between groups AT and CT at the end of $7^{\text {th }}$ experimental week $(n=3)$. b) Comparison between sub-group ATEEP, sub-group AT-NS, and group CT at the end of $11^{\text {st }}$ experimental week $(n=6)$ * indicates significant difference at the $p<0.05$ level.

detected in these parameters between sub-group AT-EEP and group CT.

Administration of alcohol also increased plasma TG and TC concentrations. However, significant elevation was only detected in the TC level in sub-group AT-NS $(1.49 \pm 0.09 \mathrm{mmoL} / \mathrm{L})$, which was significantly higher than that in sub- group AT-EEP $(1.27 \pm 0.02 \mathrm{mmoL} / \mathrm{L})$ and group CT $(1.23 \pm 0.04 \mathrm{mmoL} / \mathrm{L})$. Co-administration of EEP with alcohol helped to significantly decrease plasma TC level. As a result, no significant differences in $\mathrm{TG}$ and $\mathrm{TC}$ concentrations were detected between sub-group AT-EEP and group CT. Our results demonstrated that EEP was effective 
in restoring these parameters to the normal levels represented by the control animals in group CT.

\section{TG CONTENT IN THE LIVER}

The TG contents in the liver tissue were $22.9 \pm 1.43$ $\mathrm{mg} / \mathrm{g}, 30.35 \pm 1.24 \mathrm{mg} / \mathrm{g}$, and $35.29 \pm 3.15 \mathrm{mg} / \mathrm{g}$ for group CT, sub-group AT-EEP, and sub-group AT-NS, respectively. No significant differences were detected among different groups. However, four-week's treatment of EEP did cause a reduction of TG content in the liver tissue.

\section{HISTOPATHOLOGICAL CHANGES}

Histological examination of liver sections revealed that rats in group CT, either 29-week old (at the end of the $7^{\text {th }}$ experimental week, Figure S2a) or 33-week old (at the end of the $11^{\text {st }}$ experimental week, Figure 3a), had clear lobular architecture and normal structure of hepatocytes. Liver sections from group AT (receiving alcohol treatment for 7 weeks) showed the formation of lipid vacuoles in hepatocytes, which indicated the development of steatosis (Figure S2b). After 4-week further administration of alcohol and normal saline, rats in sub-group AT-NS (Figure 3b) exhibited macro-vesicular steatosis, sinusoidal vascular congestion, enlarged and rounded hepatocytes. Those pathological changes were significantly attenuated by administration of EEP. Liver sections from sub-group AT-EEP revealed regular hepatic architecture (Figure 3c). Polyhedral hepatocytes were radiating outwards from central vein. The incidence of lipid accumulation was significantly decreased and much less vascular congestion was observed, which manifested good recovery from alcohol-induced fatty liver.

\section{AGILENT WHOLE GENOME OLIGO MICROARRAY}

Global microarray analysis, performed on the liver tissues from sub-groups AT-NS and AT-EEP, identified one set of differentially expressed genes
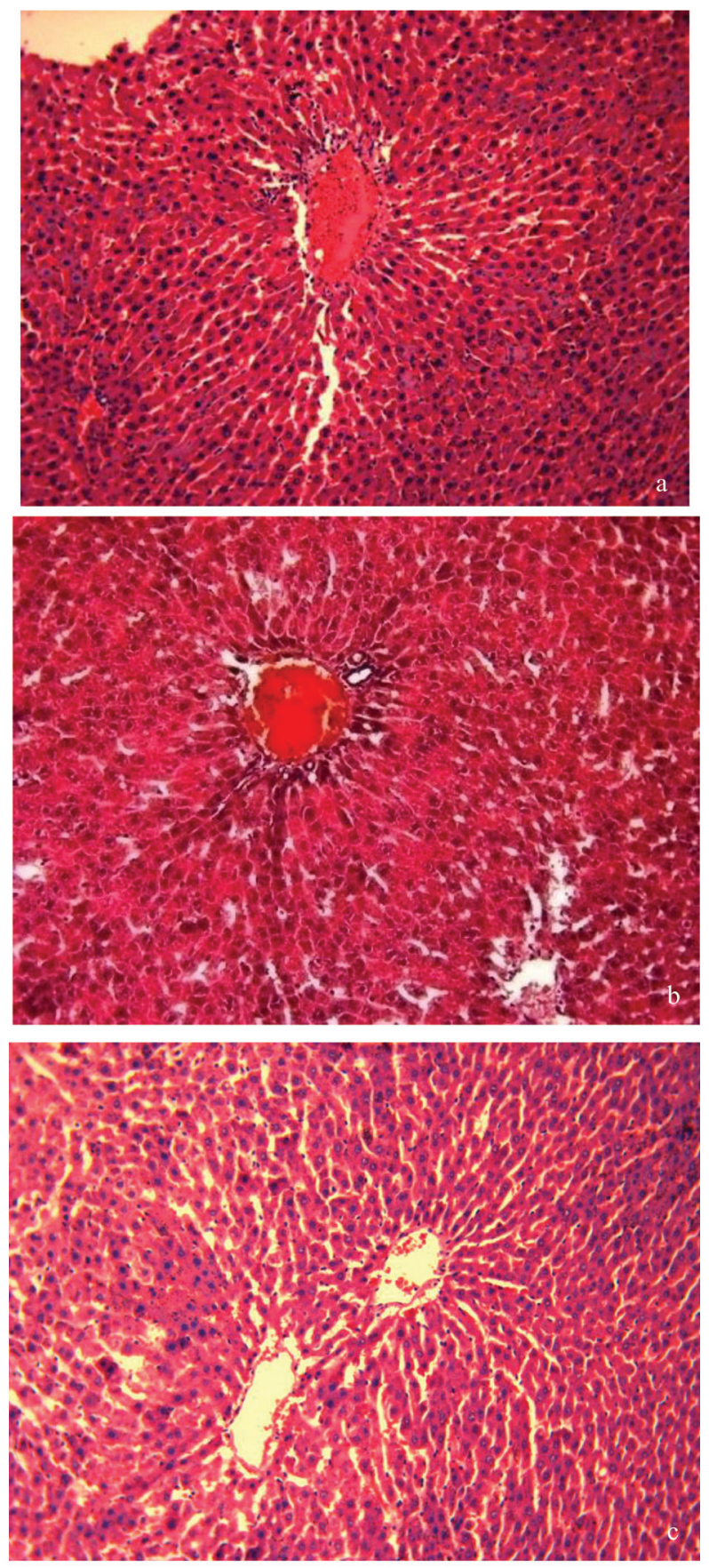

Figure 3 - Histological features of representative liver sections. a) Group CT, control; b) Sub-group AT-NS, treated with alcohol and co-administered with normal saline; c) Subgroup AT-EEP, treated with alcohol and co-administered with EEP.

(DEGs). Genes whose relative expression levels differed by more than 2.0-fold between two subgroups were screened for further analysis. 


\section{GENE ONTOLOGY (GO) AND PATHWAY ANALYSIS}

The hepatic expressions of 566 unique genes were significantly altered when sub-group AT-EEP was compared with sub-group AT-NS. Of which, 228 and 338 genes were significantly up- and downregulated in sub-group AT-EEP, respectively. Significantly enriched GO terms $(p<0.05)$ in which these EEP-responsive DEGs involved were then identified by DAVID functional annotation tool (GOTERM_BP_FAT).

The top 20 statistically over-represented GO BP (biological process) terms were shown in Figure 4. The GO BP terms for genes significantly up-regulated in sub-group AT-EEP were mainly associated with lipid metabolism. EEP administration up-regulated the expression of these genes involved in fatty acid (FA) metabolic process, FA oxidation, lipid oxidation (Figure 4a), as well as drug and xenobiotic metabolic processes. On the contrary, transcriptional expressions of those genes participated in defense and immune responses, ion homeostasis, as well as responses to wounding, bacterium, external and chemical stimulus, which were significantly up-regulated as a result of alcohol consumption, were markedly reduced after co-administration of EEP (Figure 4b). The EEP-induced significant pathways mainly included metabolism of xenobiotics by cytochrome P450 ( $p=6.10 \mathrm{E}-07$, FDR $=6.50 \mathrm{E}-04)$, biosynthesis of unsaturated fatty acids ( $p=9.40 \mathrm{E}-06, \mathrm{FDR}=$ $1.00 \mathrm{E}-02)$, and drug metabolism ( $p=2.70 \mathrm{E}-05$, $\mathrm{FDR}=2.90 \mathrm{E}-02$ ).

Results from microassay indicated that genes involved in FA oxidation, such as Acot 1 and Acot4 (acyl-CoA thioesterase 1 and 4), were significantly up-regulated, while genes involved in lipogenesis, such as PKLR (pyruvate kinase, liver and RBC), $F A S N$ (fatty acid synthase), SCD1 (stearoyl-CoA desaturase 1), and FABP5 (fatty acid binding protein 5 ), were significantly down-regulated in sub-group AT-EEP when compared with sub-group AT-NS.

\section{DISCUSSION}

Liver is the primary organ for the metabolism of alcohol, which makes liver the major target of alcohol-induced injury (Yoon et al. 2012). In this study, male Wistar rats with alcohol-induced fatty liver has been induced by 7-week administration of alcohol, which was demonstrated by significantly increased hepatic lipid accumulation and significantly elevated ALT level in plasma. In the present study, significantly higher RLW was detected in rats receiving alcohol treatment for 7 weeks. Dyslipidaemia manifested by significantly higher plasma TC level was observed after 11-week treatment of alcohol. ALT consistently exhibited significant difference between alcohol-treated rats and the control. All these results indicated the alcohol-induced liver injuries.

Despite the complex and multi-factorial processes that involved in the development of alcohol-induced fatty liver, the enhancement of lipid synthesis has been considered as an important biochemical mechanism contributing to its development (Diehl 2002, Sozio and Crabb 2008). Results from previous researches demonstrated that stimulated lipogenesis in hepatocytes as a result of alcohol ingestion was occurred with increased expression of lipogenic genes that are regulated by the transcription factor of SREBP-1 (sterol-regulatory-element binding protein-1) (You and Crabb 2004). In the present study, results from microarray confirmed that 4-week coadministration of EEP with alcohol significantly down-regulated the expressions of well-known SREBP-1 responsive lipogenic genes, FASN, SCD1(Shimomura et al. 1998, Tabor et al. 1999), and FABP5 (Maxwell et al. 2003), which might be helpful in preventing the hepatic lipid accumulation. 


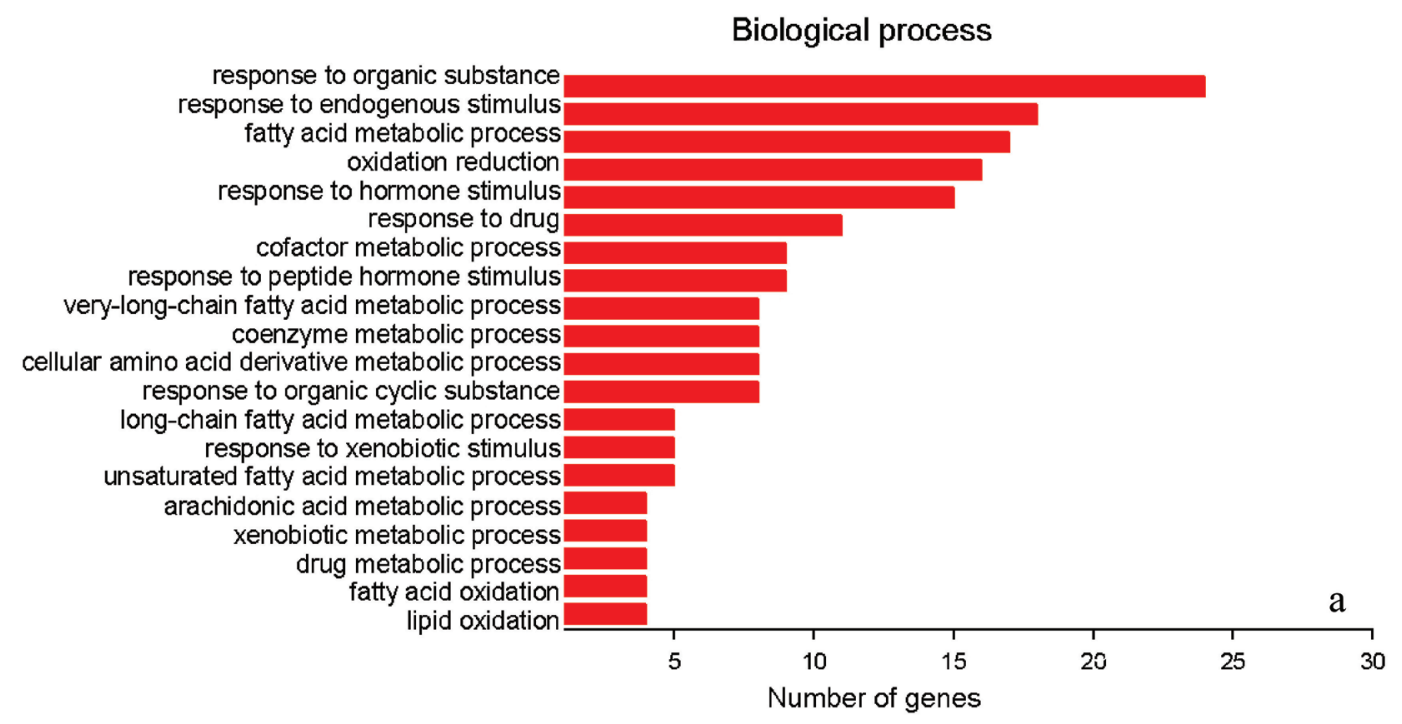

Biological process

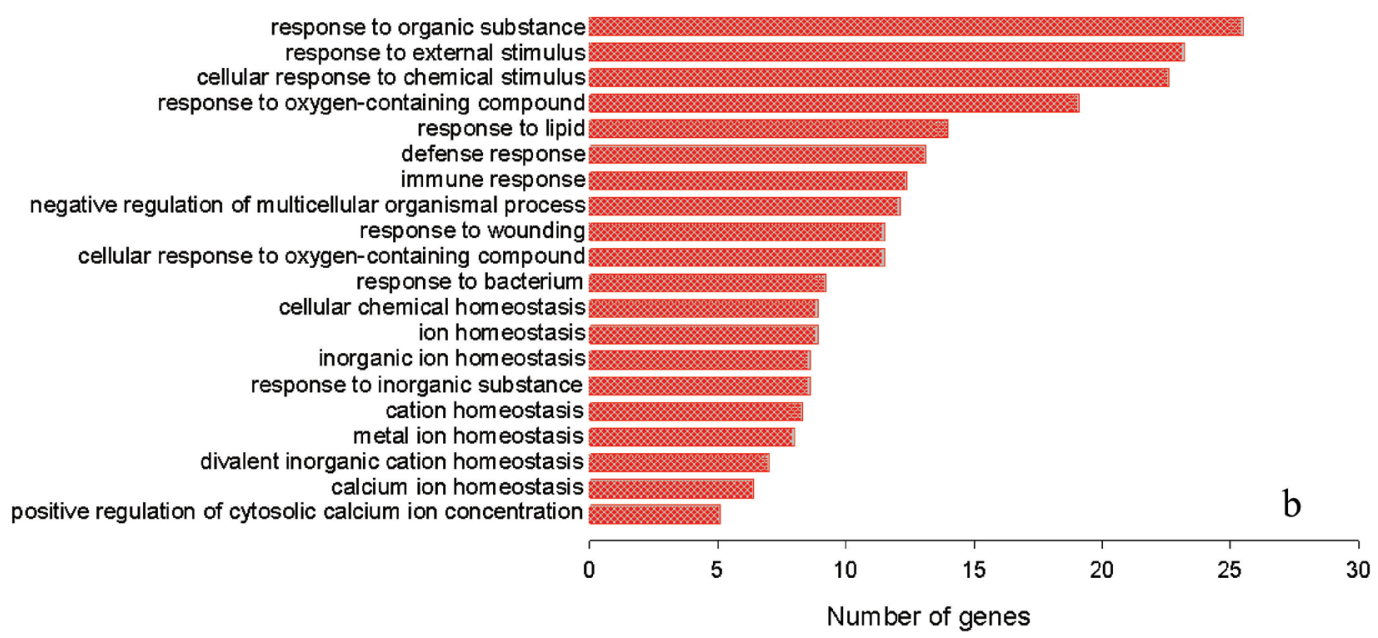

Figure 4 - The top 20 gene ontology (GO) biological process (BP) terms with the highest statistical significance. The vertical axis was the GO BP terms, and the horizontal axis was the number of genes. a) The top 20 significant GO categories for significantly up-regulated DEGs in sub-group AT-EEP; b) The top 20 significant GO categories for significantly down-regulated DEGs in sub-group AT-EEP.

During de novo lipogenesis, FASN is considered to be a determinant of the maximum capacity of the liver to synthesize FAs (Wu et al. 2011) and thus an attractive target for therapeutic intervention of diseases associated with elevated lipogenesis (Angeles and Hudkins 2016). Results from our study demonstrated that EEP could significantly down-regulate the hepatic expression of FASN in alcohol-treated rats, which indicated the inhibition of hepatic lipogenesis even in the face of continued alcohol consumption and opened opportunities for expanding the therapeutic utility of EEP in AFLD.

SCD1 is a key enzyme for the synthesis of monounsaturated FAs (Yao et al. 2017). Overexpression of SCD1 was found to be associated with significantly increased rate of TG synthesis 
and decreased rate of FA oxidation (Hulver et al. 2005, Listenberger et al. 2003). On the contrary, SCD1 deficiency brought about such physiological changes as activation of FA oxidation, reduced TG storage, and down-regulated expression of lipogenic genes (Cohen et al. 2002, Miyazaki et al. 2000, Ntambi et al. 2002). The significantly down-regulated transcriptional expression of $S C D 1$ observed in EEP-treated rats may contribute to the decreased lipid synthesis and enhanced FA utilization which helped to ameliorate alcoholinduced fatty liver.

FABP 5 was observed to be up-regulated in circumstances with disturbed lipid profiles (Hertzel and Bernlohr 2000). The deletion of FABP5 was reported to be associated with decreased level of liver injury, enhanced anti-inflammatory response, and resistance to diet-induced fatty liver disease (Maeda et al. 2005, Moore et al. 2015). Coadministration of EEP with alcohol resulted in the significant down-regulation of hepatic expression of FABP5, which might be linked to less liver injury and reduced pro-inflammatory response.

It was also worth noting that the mRNA level of PKLR, encoding one the rate-limiting enzymes in glycolysis, was significantly decreased in alcohol-treated rats co-administered with EEP. As a consequence, the glycolysis pathway was inactivated and led to the production of less pyruvate (Boin et al. 2006). Since pyruvate is the main carbon source for FA synthesis, the overall net effect of decreased PKLR gene expression was to decrease FA biosynthesis.

All together, EEP treatment inactivated not only genes directly responsible for FAs synthesis, but also genes responsible for the production of the two-carbon unit (acetyl-CoA) required for FA synthesis, which was effective in inhibiting lipogenesis and ameliorating lipid accumulation in the liver.

Results from the present study also demonstrated that EEP stimulated the expression of genes participated in FA oxidation, which included Acot1 and Acot4. Localized in the cytosol (Acot1) and peroxisome (Acot4), these two enzymes play important roles in FA metabolism by hydrolyzing long-chain acyl-CoAs thioesters (Kirkby et al. 2010). Up-regulation of Acot1 was supposed to maintain the rate of FA oxidation, even under the circumstance of FA oversupply (Fujita et al. 2011). Studies in mice showed that over-expression of Acot1 was associated with reduced generation of reactive oxygen species arising from mitochondria (Yang et al. 2012). Studies in rats indicated that up-regulation of Acot4 transcripts contributed to hepatocellular protection against glutathione depletion-induced oxidative stress (Yamauchi et al. 2011). The observed up-regulation of hepatic expression of Acot1 and Acot4 indicated the stimulation of FA oxidation in EEP-treated rats along with reduced oxidative stress. Our results were compatible with previous reports that demonstrated increased hepatic expressions of Acot members after dietary supplementation of lipid-lowering bioactive food compound (Pashaj et al. 2013, Yi et al. 2013). With the concomitant down-regulation of lipid biosynthesis after EEP administration, the enhanced FA oxidation would be an important step for the reversal of fat accumulation in the liver tissue.

Flavonoids are the major components of EEP, such as pinocembrin, naringin, chrysin, and galangin. A wide spectrum of hepatoprotective effects have been attributed to them. For example, pinocembrin has been reported to prevent thioacetamide (TAA)induced liver cirrhosis (Chen et al. 2008). Studies, both in vivo (Zhou et al. 2018) and in vitro (Said et al. 2018), demonstrated its potent anti-fibrotic effects. Naringin has been reported to have antifibrotic efficacy in TAA-induced hepatic fibrosis in rats (El-Mihi et al. 2017), exert protective effects against chemicals-induced hepatoxicity (Pari and Amudha 2011), alleviate the adverse effects of ethanol ingestion in rats by increasing ethanol 
and lipid metabolism (Seo et al. 2003). In the intragastric fed rat model of ALD, naringin also showed such beneficial influences as inhibition of steatosis, necrosis, and fibrosis (Oliva et al. 2008). As for chrysin, it has global hepatoprotective effects, including preventing oxidative damage due to chronic ethanol consumption (Tahir and Sultana 2011), reducing ethanol-induced liver injury (Sathiavelu et al. 2009), ameliorating $\mathrm{CCl}_{4}$-induced acute liver damage by counteracting the activation of inflammation signaling pathways (Hermenean et al. 2017), and alleviating hepatic injury caused by administration of cisplatin (Rehman et al. 2014). Its anti-fibrotic effect on regression of $\mathrm{CCl}_{4}$-stimulated liver fibrosis was also recently documented (Balta et al. 2015, 2018). Galangin could suppress the proliferation of hepatocellular carcinoma cells (Wang et al. 2014, 2017), ameliorate concanavalin A-induced liver damage in mice (Luo et al. 2015), provide hepatoprotective effects in acetaminophentreated mice by decreasing the hepatic oxidative stress and increasing hepatic glutathione level (Tsai et al. 2015). In a $\mathrm{CCl}_{4}$-induced rat liver fibrosis model, galangin exerted anti-fibrotic effects (Wang et al.2013). The anti-adipogenic activity of galangin was also documented (Jung et al. 2012). Based on these beneficial roles that these flavonoids played in various hepatic diseases, we suggest that the hepatoprotective activities of EEP observed in this study are mainly due to the flavonoids in propolis.

Collectively, our results indicated that the beneficial effects that EEP exerted on the inhibition of hepatic lipid accumulation were due to not only decreases in lipid synthesis but also increases in the rate of FA oxidation, which was effective in alleviating liver steatosis induced by alcohol consumption. Nevertheless, it is important to take into account that only results from the transcription level were obtained. Further research measuring the activities of enzymes participated in lipid metabolism are needed to determine the EEP-responsive effects. Moreover, studies at the translational level might also contribute to verify results of the present study.

In summary, the present study provided evidence that the polyphenol-rich components of EEP could significantly alleviate alcoholic fatty liver in male Wistar rats. The therapeutic effects of EEP might be mediated by modulation of such metabolic processes as lipid biosynthesis and FA oxidation. These effects associated with decreased plasma levels of ALT, ALP, and TC contributed to ameliorate alcohol-induced fatty liver. Our results suggested that propolis could potentially be developed as a valuable source of functional food ingredients for protecting against the onset of alcoholic hepatic steatosis.

\section{ACKNOWLEDGMENTS}

This work was financially supported by the Department of Science and Technology of Jiangsu Province, China (Grant No. 20151216000105).

\section{AUTHOR CONTRIBUTIONS}

BZ was responsible for the design and implementation of this work. MHY drafted the original manuscript. MHY, MTX, JC, and JJ conducted the GC-MS analysis, serological analysis, liver histopathology studies, and microarray analyses. WHW and SMY helped developed the animal model. FBJ and BZ supervised the conduction of the whole experiment. All authors have read and approved the final manuscript.

\section{REFERENCES}

ALTAMIRANO J AND BATALLER R. 2011. Alcoholic liver disease: pathogenesis and new targets for therapy. Nat Rev Gastroenterol Hepatol 8: 491-501.

ANDRITOIU CV, OCHIUZ L, ANDRITOIU V AND POPA M. 2014. Effect of apitherapy formulations against carbon tetrachloride-induced toxicity in Wistar rats after three weeks of treatment. Molecules 19: 13374-13391. 
ANGELES TS AND HUDKINS RL. 2016. Recent advances in targeting the fatty acid biosynthetic pathway using fatty acid synthase inhibitors. Expert Opin Drug Discov 11: 1187-1199.

BABATUNDE IR, ABDULBASIT A, OLADAYO MI, OLASILE OI, OLAMIDE FR AND GBOLAHAN BW. 2015. Hepatoprotective and pancreatoprotective properties of the ethanolic extract of Nigerian propolis. J Intercult Ethnopharmacol 4: 102-108.

BALTA C, CICEU A, HERMAN H, ROSU M, BOLDURA OM AND HERMENEAN A. 2018. Dose-dependent antifibrotic effect of chrysin on regression of liver fibrosis: the role in extracellular matrix remodeling. Dose Response 16: 1559325818789835 .

BALTA C, HERMAN H, BOLDURA OM, GASCA I, ROSU M, ARDELEAN A AND HERMENEAN A. 2015. Chrysin attenuates liver fibrosis and hepatic stellate cell activation through TGF-beta/Smad signaling pathway. Chem Biol Interact 240: 94-101.

BOIN IFSF, SILVA OC, SOUZA MEJ, SANTOS AC AND LEONARDI LS. 2006. Pyruvate kinase activation and lipoperoxidation after selective hepatic ischemia in Wistar rats. Acta Cir Bras 21 (Suppl 1): 19-23.

CHEN CS, WU CH, LAI YC, LEE WS, CHEN HM, CHEN RJ, CHEN LC, HO YS AND WANG YJ. 2008. NFkappaB-activated tissue transglutaminase is involved in ethanol-induced hepatic injury and the possible role of propolis in preventing fibrogenesis. Toxicology 246: 148157.

COHEN P, MIYAZAKI M, SOCCI ND, HAGGEGREENBERG A, LIEDTKE W, SOUKAS AA, SHARMA R, HUDGINS LC, NTAMBI JM AND FRIEDMAN JM. 2002. Role for stearoyl-CoA desaturase-1 in leptin-mediated weight loss. Science 297: 240-243.

DIEHL AM. 2002. Liver disease in alcohol abusers: clinical perspective. Alcohol 27: 7-11.

DONOHUE TM JR. 2007. Alcohol-induced steatosis in liver cells. World J Gastroenterol 13: 4974-4978.

EL-MIHI KA， KENAWY HI， EL-KAREF A, ELSHERBINY NM AND EISSA LA. 2017. Naringin attenuates thioacetamide-induced liver fibrosis in rats through modulation of the PI3K/Akt pathway. Life Sci 187: 50-57.

FRENCH BA, DEDES J, BARDAG-GORCE F, LI J, WILSON L, FU P, NAN L AND FRENCH SW. 2005. Microarray analysis of gene expression in the liver during the urinary ethanol cycle in rats fed ethanol intragastrically at a constant rate. Exp Mol Pathol 79: 87-94.

FUJITA M, MOMOSE A, OHTOMO T, NISHINOSONO A, TANONAKA K, TOYODA H, MORIKAWA M AND YAMADA J. 2011. Upregulation of fatty acyl-CoA thioesterases in the heart and skeletal muscle of rats fed a high-fat diet. Biol Pharm Bull 34: 87-91.

GAO B AND BATALLER R. 2011. Alcoholic liver disease: pathogenesis and new therapeutic targets. Gastroenterology 141: $1572-1585$.

HERMENEAN A, MARIASIU T, NAVARROGONZALEZ I, VEGARA-MESEGUER J, MIUTESCU E, CHAKRABORTY S AND PEREZ-SANCHEZ H. 2017. Hepatoprotective activity of chrysin is mediated through TNF-alpha in chemically-induced acute liver damage: An in vivo study and molecular modeling. Exp Ther Med 13: 1671-1680.

HERTZEL AV AND BERNLOHR DA. 2000. The mammalian fatty acid-binding protein multigene family: molecular and genetic insights into function. Trends Endocrinol Metab 11: 175-180.

HUANG DAW, SHERMAN BT AND LEMPICKI RA. 2009. Systematic and integrative analysis of large gene lists using DAVID bioinformatics resources. Nat Protoc 4: 44-57.

HULVER MW ET AL. 2005. Elevated stearoyl-CoA desaturase-1 expression in skeletal muscle contributes to abnormal fatty acid partitioning in obese humans. Cell Metab 2: 251-261.

ISIDOROV VA, SZCZEPANIAK L AND BAKIER S. 2014. Rapid GC/MS determination of botanical precursors of Eurasian propolis. Food Chem 142: 101-106.

JUNG CH, JANG SJ, AHN J, GWON SY, JEON TI, KIM TW AND HA TY. 2012. Alpinia officinarum inhibits adipocyte differentiation and high-fat diet-induced obesity in mice through regulation of adipogenesis and lipogenesis. J Med Food 15: 959-967.

KIM DO, JEONG SW AND LEE CY. 2003. Antioxidant capacity of phenolic phytochemicals from various cultivars of plums. Food Chem 81: 321-326.

KIRKBY B, ROMAN N, KOBE B, KELLIE S AND FORWOOD JK. 2010. Functional and structural properties of mammalian acyl-coenzyme A thioesterases. Prog Lipid Res 49: 366-377.

LIN SC, LIN YH, CHEN CF, CHUNG CY AND HSU SH. 1997. The hepatoprotective and therapeutic effects of propolis ethanol extract on chronic alcohol-induced liver injuries. Am J Chin Med 25: 325-332.

LISTENBERGER LL, HAN X, LEWIS SE, CASES S, FARESE RVJR, ORY DS AND SCHAFFER JE. 2003 Triglyceride accumulation protects against fatty acidinduced lipotoxicity. Proc Natl Acad Sci USA 100: 3077 3082.

LIU H, QI X, CAO S AND LI P. 2014. Protective effect of flavonoid extract from Chinese bayberry (Myrica rubra Sieb. et Zucc.) fruit on alcoholic liver oxidative injury in mice. J Nat Med 68: 521-529. 
LUO QQ, ZHU LP, DING JY, ZHUANG X, XU LL AND CHEN FX. 2015. Protective effect of galangin in Concanavalin A-induced hepatitis in mice. Drug Des Devel Ther 9: 2983-2992.

MAEDA K ET AL. 2005. Adipocyte/macrophage fatty acid binding proteins control integrated metabolic responses in obesity and diabetes. Cell Metab 1: 107-119.

MAXWELL KN, SOCCIO RE, DUNCAN EM, SEHAYEK E AND BRESLOW JL. 2003. Novel putative SREBP and LXR target genes identified by microarray analysis in liver of cholesterol-fed mice. J Lipid Res 44: 2109-2119.

MIYAZAKI M, KIM YC, GRAY-KELLER MP, ATTIE AD AND NTAMBI JM. 2000. The biosynthesis of hepatic cholesterol esters and triglycerides is impaired in mice with a disruption of the gene for stearoyl-CoA desaturase 1. J Biol Chem 275: 30132-30138.

MOORE SM, HOLT VV, MALPASS LR, HINES IN AND WHEELER MD. 2015. Fatty acid-binding protein 5 limits the anti-inflammatory response in murine macrophages. Mol Immunol 67: 265-275.

NAKAJIMA M, ARIMATSU K, MINAGAWA T, MATSUDA Y, SATO K, TAKAHASHI N, NAKAJIMA T AND YAMAZAKI K. 2016. Brazilian propolis mitigates impaired glucose and lipid metabolism in experimental periodontitis in mice. BMC Complement Altern Med 16: 329.

NTAMBI JM, MIYAZAKI M, STOEHR JP, LAN H, KENDZIORSKI CM, YANDELL BS, SONG Y, COHEN P, FRIEDMAN JM AND ATTIE AD. 2002. Loss of stearoyl-CoA desaturase-1 function protects mice against adiposity. Proc Natl Acad Sci USA 99: 1148211486.

OLIVA J, FRENCH BA, LI J, BARDAG-GORCE F, FU P AND FRENCH SW. 2008. Sirt1 is involved in energy metabolism: the role of chronic ethanol feeding and resveratrol. Exp Mol Pathol 85: 155-159.

ORSOLIC N, SIROVINA D, KONCIC MZ, LACKOVIC G AND GREGOROVIC G. 2012. Effect of Croatian propolis on diabetic nephropathy and liver toxicity in mice. BMC Complement Altern Med 12: 117.

OSES SM, PASCUAL-MATE A, FERNANDEZ-MUINO MA, LOPEZ-DIAZ TM AND SANCHO MT. 2016. Bioactive properties of honey with propolis. Food Chem 196: 1215-1223.

O'SHEA RS, DASARATHY S AND MCCULLOUGH AJ. 2010. Alcoholic liver disease. Hepatology 51: 307-328.

PARI L AND AMUDHA K. 2011. Hepatoprotective role of naringin on nickel-induced toxicity in male Wistar rats. Eur J Pharmacol 650: 364-370.

PARK HY, CHOI HD, EOM H AND CHOI I. 2013. Enzymatic modification enhances the protective activity of citrus flavonoids against alcohol-induced liver disease. Food Chem 139: 231-240.
PASHAJ A, YI X, XIA M, CANNY S, RIETHOVEN JJ AND MOREAU R. 2013. Characterization of genomewide transcriptional changes in liver and adipose tissues of ZDF (fa/fa) rats fed R-alpha-lipoic acid by next-generation sequencing. Physiol Genomics 45: 1136-1143.

PUROHIT V, GAO B AND SONG BJ. 2009. Molecular mechanisms of alcoholic fatty liver. Alcohol Clin Exp Res 33: 191-205.

REHMAN MU ET AL. 2014. Alleviation of hepatic injury by chrysin in cisplatin administered rats: probable role of oxidative and inflammatory markers. Pharmacol Rep 66: 1050-1059.

SAID MM, AZAB SS, SAEED NM AND ELDEMERDASH E. 2018. Antifibrotic mechanism of pinocembrin: impact on oxidative stress, inflammation and TGF-beta /Smad inhibition in rats. Ann Hepatol 17: 307-317.

SATHIAVELU J, SENAPATHY GJ, DEVARAJ R AND NAMASIVAYAM N. 2009. Hepatoprotective effect of chrysin on prooxidant-antioxidant status during ethanolinduced toxicity in female albino rats. J Pharm Pharmacol 61: 809-817.

SEO HJ, JEONG KS, LEE MK, PARK YB, JUNG UJ, KIM HJ AND CHOI MS. 2003. Role of naringin supplement in regulation of lipid and ethanol metabolism in rats. Life Sci 73: 933-946.

SHIMOMURA I, SHIMANO H, KORN BS, BASHMAKOV Y AND HORTON JD. 1998. Nuclear sterol regulatory element-binding proteins activate genes responsible for the entire program of unsaturated fatty acid biosynthesis in transgenic mouse liver. J Biol Chem 273: 35299-35306.

SOZIO M AND CRABB DW. 2008. Alcohol and lipid metabolism. Am J Physiol Endocrinol Metab 295: E10-16.

SUN Q, ZHANG W, ZHONG W, SUN X AND ZHOU Z. 2016. Dietary fisetin supplementation protects against alcohol-induced liver injury in mice. Alcohol Clin Exp Res 40: 2076-2084.

TABOR DE, KIM JB, SPIEGELMAN BM AND EDWARDS PA. 1999. Identification of conserved ciselements and transcription factors required for sterolregulated transcription of stearoyl-CoA desaturase 1 and 2 . J Biol Chem 274: 20603-20610.

TAHIR M AND SULTANA S. 2011. Chrysin modulates ethanol metabolism in Wistar rats: a promising role against organ toxicities. Alcohol Alcohol 46: 383-392.

TSAI MS, CHIEN CC, LIN TH, LIU CC, LIU RH, SU HL, CHIU YT AND WANG SH. 2015. Galangin prevents acute hepatorenal toxicity in novel propacetamol-induced acetaminophen-overdosed mice. J Med Food 18: 11871197. 
WAGH VD. 2013. Propolis: a wonder bees product and its pharmacological potentials. Adv Pharmacol Sci 2013: 308249.

WALI AF, AVULA B, ALI Z, KHAN IA, MUSHTAQ A, REHMAN MU, AKBAR S AND MASOODI MH. 2015. Antioxidant, hepatoprotective potential and chemical profiling of propolis ethanolic extract from Kashmir Himalaya region using UHPLC-DAD-QToF-MS. Biomed Res Int 2015: 393462.

WANG X, GONG G, YANG W, LI Y, JIANG M AND LI L. 2013. Antifibrotic activity of galangin, a novel function evaluated in animal liver fibrosis model. Environ Toxicol Pharmacol 36: 288-295.

WANG YJ, LIN BY, LI HM, LAN LB, YU HJ, WU S, WU J AND ZHANG HT. 2017. Galangin suppresses hepatocellular carcinoma cell proliferation by reversing the Warburg effect. Biomed Pharmacother 95: 1295-1300.

WANG YJ, WU J, LIN BY, LI X, ZHANG HT, DING H, CHEN XY, LAN LB AND LUO H. 2014. Galangin suppresses HepG2 cell proliferation by activating the TGF- $\beta$ receptor/ Smad pathway. Toxicology 326: 9-17.

WANG Z, SU B, FAN S, FEI H AND ZHAO W. 2015. Protective effect of oligomeric proanthocyanidins against alcohol-induced liver steatosis and injury in mice. Biochem Biophys Res Commun 458: 757-762.

WU M ET AL. 2011. Antidiabetic and antisteatotic effects of the selective fatty acid synthase (FAS) inhibitor platensimycin in mouse models of diabetes. Proc Natl Acad Sci USA 108: 5378-5383.

YAMAUCHI S, KIYOSAWA N, ANDO Y, WATANABE $\mathrm{K}$, NIINO N, ITO K, YAMOTO T, MANABE S AND SANBUISSHO A. 2011. Hepatic transcriptome and proteome responses against diethyl maleate-induced glutathione depletion in the rat. Arch Toxicol 85: 10451056.

YANG S ET AL. 2012. Protective effects of acyl-coA thioesterase 1 on diabetic heart via PPARalpha/PGC1alpha signaling. PLoS ONE 7: e50376.
YAO D, LUO J, HE Q, SHI H, LI J, WANG H, XU H, CHEN Z, YI Y AND LOOR JJ. 2017. SCD1 alters longchain fatty acid (LCFA) composition and its expression is directly regulated by SREBP-1 and PPARgamma 1 in dairy goat mammary cells. J Cell Physiol 232: 635-649.

YI X, PASHAJ A, XIA M AND MOREAU R. 2013. Reversal of obesity-induced hypertriglyceridemia by (R)alpha-lipoic acid in ZDF (fa/fa) rats. Biochem Biophys Res Commun 439: 390-395.

YOON SJ, KOH EJ, KIM CS, ZEE OP, KWAK JH, JEONG WJ, KIM JH AND LEE SM. 2012. Agrimonia eupatoria protects against chronic ethanol-induced liver injury in rats. Food Chem Toxicol 50: 2335-2341.

YOU M AND CRABB DW. 2004. Recent advances in alcoholic liver disease II. Minireview: molecular mechanisms of alcoholic fatty liver. Am J Physiol Gastrointest Liver Physiol 287: G1-G6.

ZHOU F, WANG A, LI D, WANG Y AND LIN L. 2018. Pinocembrin from Penthorum chinense Pursh suppresses hepatic stellate cells activation through a unified SIRT3TGF-beta-Smad signaling pathway. Toxicol Appl Pharmacol 341: 38-50.

\section{SUPPLEMENTARY MATERIAL}

Table SI - Retention times (RTs) and percentages of relative area $(\%)$ of chemical constituents in EEP detected by GC-MS.

Table SII - The body weight, organ weight, relative organ weight, and serum biochemical indexes of rats in different groups.

Figure S1 - Body weights of rats in different experimental groups.

Figure S2 - Histological features of represrntative liver sectioons. 